doi: $10.2306 /$ scienceasia1513-1874.2014.40.212

\title{
Association of adenosine triphosphate-binding cassette transporter A1 gene polymorphism with lipid profiles and early-onset type 2 diabetes
}

\author{
Chieh-Hsiang Lu ${ }^{\mathrm{a}, \mathrm{b}, \mathrm{c}}$, Wen-Ling Liao ${ }^{\mathrm{d}, \mathrm{e}}$, Tzu-Yuan Wang ${ }^{\mathrm{f}}$, Ching-Chu Chen ${ }^{\mathrm{f}}$, Yung-Hsiang Chen ${ }^{\mathrm{e}, \mathrm{g}}$, \\ Siu-San Tse ${ }^{\mathrm{h}}$, Yu-Chuen Huang ${ }^{\mathrm{i}, \mathrm{j}}$, Fuu-Jen Tsai ${ }^{\mathrm{i}, \mathrm{j}, \mathrm{k}, 1, *}$ \\ a Division of Endocrinology and Metabolism of Internal Medicine, \\ Ditmanson Medical Foundation Chia-Yi Christian Hospital, Chia-Yi, Taiwan \\ b Department of Business Administration, National Chung Cheng University, Chia-yi County, Taiwan \\ c TaTung Institute of Commerce and Technology, Chia-yi City, Taiwan \\ d Centre for Personalized Medicine, China Medical University Hospital, Taichung, Taiwan \\ e Graduate Institute of Integrated Medicine, China Medical University, Taichung, Taiwan \\ f Division of Endocrinology and Metabolism, Department of Medicine, China Medical University Hospital, \\ Taichung, Taiwan \\ $g$ Graduate Institute of Acupuncture Science, School of Chinese Medicine, College of Chinese Medicine, \\ China Medical University, Taichung, Taiwan \\ h Department of Surgery, Division of Urology, Tung's Taichung Metroharbor hospital \\ i College of Chinese Medicine, China Medical University, Taichung, Taiwan \\ j Department of Medical Genetics and Medical Research, China Medical University Hospital, Taichung, \\ Taiwan \\ k Department of Pediatrics, China Medical University Hospital, Taichung, Taiwan \\ 1 Department of Biotechnology and Bioinformatics, Asia University, Taichung, Taiwan
}

*Corresponding author, e-mail: d0704@www.cmuh.org.tw

\begin{abstract}
Adenosine triphosphate-binding cassette transporter A1 (ABCA1) plays an important role in lipid metabolism and is involved in diabetes. We investigated the associations between lipid profiles and an early-onset diabetic phenotype with $A B C A 1$ genotypes among 999 type 2 diabetes mellitus patients in the Han Chinese population of Taiwan. During study enrolment, blood samples were collected by venipuncture from these patients for genomic DNA isolation and serological tests, and data related to the diabetes age of onset were collected using a self-report questionnaire. Four single-nucleotide polymorphisms (SNPs) were selected for genotyping by polymerase chain reaction in each patient. The present study found that the high-density lipoprotein (HDL) levels were significantly different among patients with different genotypes at SNP rs2487039 ( $p=0.018$ ). The body mass index (BMI) was also significantly different among patients with different genotypes at SNP rs2487039, rs2230806, and rs200069 ( $p=0.009,0.004$, and 0.003, respectively). The polymorphisms at position rs10121901 in ABCA1 were statistically associated with development of early-onset type 2 diabetes mellitus $(p=0.013)$, with an odds ratio of 0.78 (95\% confidence interval: 0.64-0.95). In conclusion, an $A B C A 1$ variant is associated with HDL level, BMI, and early-onset type 2 diabetes mellitus in a specific Taiwanese population.
\end{abstract}

KEYWORDS: ABCA1, HDL, dyslipidaemia, single-nucleotide polymorphism

\section{INTRODUCTION}

Type 2 diabetes mellitus (T2DM) and its complications are a significant public health problem. The disease is responsible for blindness, renal replacement therapy, and cardiovascular interventions in a large proportion of patients, all of which have a substantial negative impact on overall health care expenditure and quality of life. The prevalence and incidence of T2DM among young adults has been increasing every year in the last two decades ${ }^{1,2}$. Studies have shown that early-onset diabetes is associated with an increased risk for complications in comparison to late-onset diabetes and that the development and progression of complications might be more rapid in the earlyonset disease $^{3}$. One hypothesis to explain these 
observations proposes that the longer disease duration and exposure to adverse risk factors for early-onset T2DM patients lead to diabetes-related complications, with significant morbidity and mortality. Another hypothesis suggests that early diagnosis of T2DM in young subjects identifies an inherently aggressive phenotype that develops more complications than lateonset disease ${ }^{4,5}$.

Current evidence indicates that the risk of developing T2DM is controlled by environmental and genetic factors. Heterogeneity, as a determinant of T2DM development, has been identified by candidate gene and genome-wide association approaches across multiple populations ${ }^{6,7}$. Obesity is one risk factor for developing T2DM. Several susceptibility genes related to lipid metabolism, such as apolipoprotein A1, lipoprotein lipase ${ }^{8,9}$, and adiponectin ${ }^{10-12}$, also have been investigated for their relationship with T2DM, but the results of these studies have been inconsistent.

Adenosine triphosphate-binding cassette transporter A1 (ABCA1) is a 2261-amino acid integral membrane protein that is highly expressed in the liver and tissue macrophages. It is a cell membrane transporter and mediates the efflux of cholesterol, phospholipids, and other lipophilic molecules from cells; transfer of these molecules from peripheral cells to lipid-poor apolipoprotein A1 is the first step in highdensity lipoprotein (HDL) particle formation ${ }^{13,14}$ by a number of metabolically active pathways. In studies of cultured cells, human HDL deficiencies and animal models have shown that $A B C A l$ is an efficient exporter of cholesterol from macrophages and other cells and is a major determinant of plasma HDL levels. Moreover, ABCA1 may play a key role in HDL metabolism and could be involved in diabetes. One study reports that cholesterol accumulation in pancreatic beta-cells could lead to insulin secretion failure in a mouse model, and may be an important component of lipotoxicity in pancreatic islets ${ }^{15}$.The selective loss of ABCA1 in pancreatic beta-cells leads to age-related progressive impairment in glucose tolerance, even in heterozygous mice ${ }^{15}$. There is genetic evidence that $A B C A l$ is involved in modulating T2DM in humans. Several $A B C A 1$ polymorphisms and mutations have been reported to decrease HDL cholesterol levels ${ }^{16-19}$, obesity ${ }^{16}$, and $\mathrm{T}_{2} \mathrm{DM}^{20,21}$ across multiple ethnic groups. In the Mexican population, subjects with the R230C polymorphism (rs9282541) in the $A B C A 1$ gene have low HDL ${ }^{19}$, increased body mass ${ }^{16}$, elevated haemoglobin $\mathrm{A}_{1 \mathrm{c}}$ levels, reduced fasting insulin, and early-onset T2DM ${ }^{22}$.

Based on these previous observations, we investigated the potential association between variability of polymorphisms in the $A B C A 1$ gene, lipid profiles, and the early-onset diabetic phenotype among the Han Chinese population of Taiwan.

\section{MATERIALS AND METHODS}

\section{Patients and data collection}

This was a cross-sectional study. A total of 999 T2DM patients over 20 years of age were recruited from China Medical University Hospital (CMUH) in Taiwan. Informed consents were obtained from all patients for this study. Diabetes was diagnosed according to medical records and fasting plasma glucose levels using the American Diabetic association (ADA) criteria ${ }^{23}$. Patients with type 1 diabetes mellitus, gestational diabetes, and maturity-onset diabetes of the young were excluded from this study. All participating patients were of Han Chinese origin as the Han Chinese account for $98 \%$ of the Taiwanese population. Data regarding age, sex, age of onset of diabetes mellitus were collected from self-report questionnaires. Based on the ADA recommended age for T2DM, screening of these patients revealed that 281 patients were $\geqslant 20$ years but $<45$ years of age at the time of diagnosis (early-onset diabetes) and 718 patients were $\geqslant 45$ years (late-onset diabetes). Weight, height, waist/hip circumference and blood pressure were measured at the time of enrolment. Blood samples were collected by venipuncture for genomic DNA isolation and serological tests, including fasting glucose, $\mathrm{HbA}_{1 \mathrm{c}}$, total cholesterol, triglyceride, HDL-cholesterol and LDL-cholesterol at the time of enrolment. The study was reviewed by the ethics committee of CMUH (IRB No. DMR99-IRB-164-2; approved 15 Nov 2011) and performed according to the tenets of the Declaration of Helsinki for research involving human subjects.

\section{SNP selection and genotyping}

We selected four single nucleotide polymorphisms (SNPs) for genotyping, including rs10121901 and rs2487039 in introns, rs2230806 (Arg219Lys) in an exon, and rs200069, with an unknown locus and designated as the official distinctive SNP of the $A B C A 1$ gene. All the selected SNPs were selected in previous studies and exhibit allele frequencies of more than $5 \%$ in the Han Chinese population ${ }^{22,24}$. Linkage disequilibrium (LD) was performed with HAPLOVIEW 4.1, and the result showed LD between rs2487039 and rs2230806 $\left(r^{2}=0.97\right)$. For genotyping, genomic DNA was extracted from peripheral blood leukocytes using a genomic DNA kit (Qiagen, Valencia, CA, USA) in accordance with the manufacturer's instruc- 
Table 1 Demographic and clinical profile of 999 type 2 diabetes mellitus patients.

\begin{tabular}{ll}
\hline Variables & Values (mean $\pm \mathrm{SD})$ \\
\hline Male: female & $489: 510$ \\
Age at study (years) & $60 \pm 11$ \\
Age of onset (years) & $51 \pm 11$ \\
Diabetes duration (years) & $9.1 \pm 7.2$ \\
HbA $_{1 \mathrm{c}}(\%)$ & $7.9 \pm 1.5$ \\
$\mathrm{BMI}_{\left(\mathrm{kg} / \mathrm{m}^{2}\right)}$ & $25.2 \pm 3.8$ \\
Total cholesterol (mg/dl) & $188 \pm 40$ \\
HDL (mg/dl) & $49 \pm 14$ \\
LDL (mg/dl) & $119 \pm 37$ \\
Triglycerides (mg/dl) & $163 \pm 123$ \\
\hline
\end{tabular}

$\mathrm{HbA}_{1 \mathrm{c}}$, haemoglobin A1c; BMI, body mass index; HDL, high-density lipoprotein cholesterol; LDL, low-density lipoprotein cholesterol

tions. Genotyping was performed using an allelespecific extension and ligation assay, according to the manufacturer's instructions (Illumina, Inc., San Diego, CA, USA).

\section{Statistical analysis}

Genotype and allele frequency distributions in the polymorphisms of T2DM patients with different phenotypes (early-onset disease, heart disease, and microvascular diseases) were analysed using the $\chi^{2}$ test or Fisher's exact test for differences in proportions. Mean values of various clinical variables were compared between groups using ANOVA, and post-hoc comparisons were performed with Bonferroni adjustment. Analysis of covariance (ANCOVA) or two-way ANOVA was used to adjust for confounding variables and the possible interactions. The odds ratio (OR) was calculated from genotype frequencies and allelic frequencies with a $95 \%$ confidence interval (CI), using unconditional logistical regression. All statistical analyses were conducted using SAS statistical software, version 9.1 (SAS Institute Inc., Cary, NC), and $p<0.05$ (two-sided) was considered significant.

\section{RESULTS}

The demographic and clinical parameters of the participants are summarized in Table 1 . To investigate the effect of genotype on clinical serology lipid profiles and body mass index (BMI) among T2DM patients, we genotyped four SNPs in the $A B C A 1$ gene. The level of BMI was significantly different among patients with different genotypes at SNP rs2487039, rs2230806, and rs200069 $(p=0.009,0.004$, and 0.003 , respectively). For pairwise comparisons, the mean value of BMI was significantly different for
Table 2 Association between $A B C A 1$ polymorphism and $\mathrm{BMI}$ and serology among T2DM patients.

\begin{tabular}{|c|c|c|c|c|c|}
\hline & $\begin{array}{c}\text { BMI } \\
\left(\mathrm{kg} / \mathrm{m}^{2}\right)\end{array}$ & $\begin{array}{c}\text { Total } \\
\text { cholesterol } \\
(\mathrm{mg} / \mathrm{dl})\end{array}$ & $\begin{array}{c}\text { HDL } \\
(\mathrm{mg} / \mathrm{dl})\end{array}$ & $\begin{array}{l}\text { LDL } \\
(\mathrm{mg} / \mathrm{dl})\end{array}$ & $\begin{array}{c}\mathrm{TG} \\
(\mathrm{mg} / \mathrm{dl})\end{array}$ \\
\hline \multicolumn{6}{|c|}{ rs10121901 } \\
\hline $\mathrm{A} / \mathrm{A}$ & $25.3 \pm 3.7$ & $187 \pm 37$ & $48 \pm 14$ & $118 \pm 36$ & $163 \pm 121$ \\
\hline $\mathrm{A} / \mathrm{G}$ & $5.0 \pm 3.9$ & $189 \pm 46$ & $49 \pm 14$ & $118 \pm 38$ & $165 \pm 133$ \\
\hline $\mathrm{G} / \mathrm{G}$ & $25.1 \pm 3.8$ & $187 \pm 38$ & $49 \pm 14$ & $118 \pm 34$ & $162 \pm 136$ \\
\hline$p$-value ${ }^{\mathrm{a}}$ & 0.488 & 0.819 & 0.865 & 0.959 & 0.949 \\
\hline \multicolumn{6}{|c|}{ rs2487039 } \\
\hline $\mathrm{C} / \mathrm{C}$ & $25.4 \pm 4.0$ & $186 \pm 40$ & $49 \pm 14$ & $116 \pm 36$ & $162 \pm 132$ \\
\hline $\mathrm{T} / \mathrm{C}$ & $25.1 \pm 3.6$ & $190 \pm 45$ & $47 \pm 13$ & $120 \pm$ & $169 \pm 121$ \\
\hline $\mathrm{T} / \mathrm{T}$ & $24.2 \pm 3.6$ & $190 \pm 33$ & $51 \pm 15$ & $121 \pm 33$ & $153 \pm 146$ \\
\hline$p$-value ${ }^{\mathrm{a}}$ & 0.009 & 0.321 & 0.018 & 0.190 & 0.443 \\
\hline \multicolumn{6}{|c|}{ rs2230806 } \\
\hline $\mathrm{A} / \mathrm{A}$ & $24.5 \pm 3.7$ & $188 \pm 33$ & $50 \pm 14$ & $118 \pm 33$ & $156 \pm 129$ \\
\hline $\mathrm{A} / \mathrm{G}$ & $5.0 \pm 3$ & $189 \pm$ & $48 \pm 13$ & $120 \pm 37$ & $165 \pm 122$ \\
\hline G/G & $25.6 \pm 4.2$ & $186 \pm 40$ & $50 \pm 14$ & $116 \pm 38$ & $166 \pm 139$ \\
\hline$p$-value ${ }^{\mathrm{a}}$ & 0.004 & 0.522 & 0.125 & 0.360 & 0.705 \\
\hline \multicolumn{6}{|l|}{ rs200069 } \\
\hline $\mathrm{C} / \mathrm{C}$ & $25.0 \pm 3.8$ & $188 \pm 39$ & $49 \pm 14$ & $117 \pm 37$ & $163 \pm 113$ \\
\hline $\mathrm{T} / \mathrm{C}$ & & $189 \pm 46$ & $49 \pm 14$ & $118 \pm 37$ & $168 \pm 154$ \\
\hline $\mathrm{T} / \mathrm{T}$ & $26.5 \pm 4.5$ & $185 \pm 35$ & $46 \pm 12$ & $123 \pm 33$ & $152 \pm 78$ \\
\hline$p$-value ${ }^{\mathrm{a}}$ & 0.003 & 0.820 & 0.091 & 0.377 & 0.573 \\
\hline
\end{tabular}

BMI, body mass index; T2DM, type 2 diabetes mellitus; HDL, high-density lipoprotein cholesterol; LDL, lowdensity lipoprotein cholesterol; TG, triglycerides

All values are presented as mean $\pm \mathrm{SD}$

${ }^{a} p$-value for ANOVA test

the following genotype pairs: between CC genotype and TT genotype at SNP rs2487039, between AA genotype and GG genotype at SNP rs2230806, and between CC genotype and TT genotype at SNP rs200069 ( $p=0.007,0.005$, and 0.003 after Bonferroni adjustment, respectively). Additionally, the levels of HDL-cholesterol were significantly different among the T2DM patients with different genotypes at SNP rs2487039 $(p=0.018)$. Subjects carrying the TC genotype had lower HDL-cholesterol levels than those carrying the TT genotype ( $p=0.042$ after Bonferroni adjustment). Furthermore, the possible confounding effect from BMI on the association between genotype and HDL level was investigated by ANCOVA analyses. The result showed that the SNP (rs2487039) effect on HDL was still significant $(p=0.019)$ after adjusting for BMI $(p<0.001)$ (the interaction term $\mathrm{BMI} * \mathrm{SNP}$ was not significant; $p=0.806$ ). However, the levels of other lipid serological markers were not significantly different among selected SNPs (Table 2).

In our database, $28 \%(n=281)$ of the subjects had early-onset T2DM (mean age at diagnosis, $39 \pm 5)$, and $72 \%(n=718)$ of the subjects had lateonset T2DM (mean age at diagnosis, $55 \pm 6$ ). The BMI and all clinical serology parameters we investigated were not significantly different between earlyand late-onset T2DM subjects (Table 3). 
Table 3 Characteristics of T2DM patients at entry, grouped by onset age.

\begin{tabular}{lccc}
\hline & \multicolumn{2}{c}{ Onset age of DM } & \\
\cline { 2 - 3 } & $<45$ & $45+$ & $p$-value \\
& $(n=281,28 \%)$ & $(n=718,72 \%)$ & \\
\hline sex (\% of males) & $164 \pm 58$ & $340 \pm 47$ & 0.002 \\
Age (years) & $50.5 \pm 9.3$ & $62.6 \pm 8.4$ & $<0.001$ \\
Age at diagnosis (years) & $38.5 \pm 4.7$ & $54.5 \pm 6.4$ & $<0.001$ \\
DM duration (years) & $12.0 \pm 8.8$ & $8.1 \pm 6.2$ & $<0.001$ \\
Body mass index (kg/m $\left.{ }^{2}\right)$ & $25.4 \pm 4.2$ & $25.0 \pm 3.6$ & 0.244 \\
Glu-AC (mg/dl) & $145 \pm 42$ & $145 \pm 43$ & 0.896 \\
Insulin (uIU/ml) & $15 \pm 13$ & $15 \pm 17$ & 0.792 \\
HbA $(\%)$ & $8.0 \pm 1.5$ & $7.9 \pm 1.5$ & 0.337 \\
Total cholesterol (mg/dl) & $190 \pm 45$ & $187 \pm 40$ & 0.286 \\
HDL (mg/dl) & $49 \pm 14$ & $49 \pm 14$ & 0.702 \\
LDL (mg/dl) & $118 \pm 36$ & $118 \pm 37$ & 0.731 \\
Triglycerides (mg/dl) & $173 \pm 167$ & $160 \pm 111$ & 0.246 \\
\hline
\end{tabular}

Glu-AC, fasting glucose

All values are presented as mean $\pm \mathrm{SD}$

We compared the allelic and genotypic frequencies of $A B C A 1$ gene polymorphisms in the Taiwanese T2DM patients with the information regarding the populations of Han Chinese in Beijing, extracted from the HapMap database (www.broadinstitute.org/ haploview, ver.4.2). The $A B C A 1$ gene polymorphisms in the Taiwanese T2DM patients were not statistically different from those in the normal Han Chinese in Beijing population. Further, we classified the T2DM patients on the basis of age of onset to determine whether $A B C A 1$ genes were associated with the early-onset phenotype. In genotype association tests, the polymorphisms at SNP rs10121901 in $A B C A 1$ were statistically associated with earlyonset T2DM $(p=0.0347)$. Furthermore, in allelic frequency analysis, the frequency of the $\mathrm{G}$ allele at position rs10121901 was significantly lower in patients with early-onset T2DM than in those with late-onset T2DM, with an OR of 0.78 (95\% CI: 0.64, 0.95) in a univariate model (Table 4). After adjusting for gender and diabetes duration, the results were still significant $(\mathrm{OR}=0.78,95 \% \mathrm{CI}=0.64-0.96)$.

\section{DISCUSSION}

ABCA1 is an efficient exporter of cholesterol from cells and a major determinant of plasma HDL levels. Several $A B C A 1$ polymorphisms and mutations have been reported to be associated with HDL cholesterol levels ${ }^{16,17}$ obesity ${ }^{16}$, and T2DM ${ }^{20,21}$, across multiple ethnic groups ${ }^{16-21}$. In this study, we investigated the influence of polymorphisms in the $A B C A l$ genes on HDL levels, BMI, and age of disease onset among T2DM patients. Previous studies have shown how $A B C A 1$ polymorphisms influence HDL-cholesterol levels in diabetes patients ${ }^{24}$ and in the general population ${ }^{16,19,25-28}$. One of the well-studied variants with documented corresponding lipid profiles is rs 2230806
(R219K); however, the results are inconsistent across various studies. Some studies show that the minor allele likely is associated with a decreased HDL level; other studies show the protective effect of a minor allele. In our present study, we did not find any association of the rs2230806 variant with any parameter of lipid profiles. We did identify a significant association between HDL level and rs2487039, which is highly linked with rs2230806. One possible factor explaining this contradictory conclusion is the different allele frequency among different ethnic groups. From a meta-analysis ${ }^{29}$, the $219 \mathrm{~K}$ allele was significantly associated with a higher level of HDL-C in Asians but not in Caucasians. Furthermore, an interaction between the $A B C A 1$ gene and BMI that could modulate HDL-cholesterol concentrations has been suggested ${ }^{28}$. We therefore investigated the possible interactions between the $A B C A 1$ gene and BMI that could affect HDL-cholesterol, but no significant interaction was found $(p>0.05)$ for interaction terms of genotype*BMI. Additionally, a significant genotype effect on HDL-cholesterol was still observed after adjusting for BMI.

Inappropriate accumulation of cholesterol leads to obesity, atherosclerosis, and diabetes. ABCA1 is thought to mediate cholesterol efflux and plays an important role in maintaining cellular cholesterol homeostasis $^{30}$. Insulin mediates the down-regulation of $A B C A 1$ expression in adipocytes, but down-regulation continues in adipocytes that are insulin-resistant ${ }^{28,31}$. In overweight subjects, who are usually hyperinsulinemic $^{32}, A B C A 1$ is more down-regulated than in normal-weight subjects ${ }^{28}$. In this cross sectional study, we found an association of $A B C A 1$ gene variants with BMI in T2DM patients, and this result is consistent with previous studies. Villarreal-Molina et al ${ }^{16}$ found an association of the $A B C A 1 \mathrm{R} 230 \mathrm{C}$ variant with BMI, and obesity-related comorbidity was observed in the Mexican mestizo general population. $\mathrm{Xu}$ et $\mathrm{al}^{33}$ also found the expression of $A B C A 1$ was reduced in overweight and obese patients and was related to a lower circulating level of the adipokine, adiponectin. Furthermore, abnormal cellular cholesterol in pancreatic beta-cells may contribute to betacell dysfunction, and ABCA1 activity is one of the important determinants of intracellular cholesterol content. Altered intracellular cholesterol homeostasis and impaired insulin secretion were observed in mice with beta-cell dysfunction for ABCA $1^{15}$. Subjects carrying loss-of-function mutations in $A B C A 1$ show impaired insulin secretion but not insulin resistance ${ }^{34,35}$. In our present study, a significant association was identified between polymorphisms within ABCAl SNP 
Table 4 Genotype and allele frequency of $A B C A 1$ markers between T2DM patients.

\begin{tabular}{|c|c|c|c|c|c|c|}
\hline & \multicolumn{2}{|c|}{ Onset age of DM } & \multirow[b]{2}{*}{$\begin{array}{c}\mathrm{CHB}^{\mathrm{a}} \\
N(\%)\end{array}$} & \multirow[b]{2}{*}{$p$-value ${ }^{\mathrm{b}}$} & \multirow[b]{2}{*}{$p$-value ${ }^{c}$} & \multirow[b]{2}{*}{$\mathrm{OR}^{\mathrm{d}}(95 \% \mathrm{CI})$} \\
\hline & $\begin{array}{c}<45 \\
N(\%)\end{array}$ & $\begin{array}{c}45+ \\
N(\%)\end{array}$ & & & & \\
\hline \multicolumn{7}{|c|}{ rs10121901 } \\
\hline $\mathrm{A} / \mathrm{A}$ & $109(39 \%)$ & $219(30 \%)$ & $24(29 \%)$ & & & 1 \\
\hline $\mathrm{A} / \mathrm{G}$ & $129(46 \%)$ & $361(50 \%)$ & $43(52 \%)$ & & & $0.72(0.53-0.97)$ \\
\hline G/G & $43(15 \%)$ & $138(19 \%)$ & $16(19 \%)$ & 0.0347 & 0.7648 & $0.63(0.41-0.95)$ \\
\hline A allele & $347(62 \%)$ & $799(56 \%)$ & $91(55 \%)$ & & & \\
\hline G allele & $215(38 \%)$ & $637(44 \%)$ & $75(45 \%)$ & 0.0131 & 0.5254 & $0.78(0.64-0.95)$ \\
\hline \multicolumn{7}{|c|}{ rs2487039 } \\
\hline $\mathrm{C} / \mathrm{C}$ & $128(46 \%)$ & $338(47 \%)$ & $31(37 \%)$ & & & 1 \\
\hline $\mathrm{T} / \mathrm{C}$ & $126(45 \%)$ & $293(41 \%)$ & $41(49 \%)$ & & & $1.14(0.85-1.52)$ \\
\hline $\mathrm{T} / \mathrm{T}$ & $27(10 \%)$ & $87(12 \%)$ & $11(13 \%)$ & 0.3684 & 0.2633 & $0.82(0.51-1.32)$ \\
\hline $\mathrm{C}$ allele & $382(68 \%)$ & $969(68 \%)$ & $103(62 \%)$ & & & 1 \\
\hline $\mathrm{T}$ allele & $180(32 \%)$ & $467(32 \%)$ & $63(38 \%)$ & 0.8325 & 0.1420 & $0.98(0.79-1.20)$ \\
\hline \multicolumn{7}{|c|}{ rs2230806 } \\
\hline $\mathrm{A} / \mathrm{A}$ & $51(18 \%)$ & $127(18 \%)$ & $18(22 \%)$ & & & $1.06(0.71-1.59)$ \\
\hline $\mathrm{A} / \mathrm{G}$ & $136(48 \%)$ & $342(48 \%)$ & $39(47 \%)$ & & & $1.05(0.77-1.44)$ \\
\hline $\mathrm{G} / \mathrm{G}$ & $94(34 \%)$ & $249(35 \%)$ & $26(13 \%)$ & 0.9335 & 0.6452 & 1 \\
\hline A allele & $238(42 \%)$ & $596(42 \%)$ & $75(45 \%)$ & & & $1.04(0.85-1.26)$ \\
\hline G allele & $324(58 \%)$ & $840(58 \%)$ & $91(55 \%)$ & 0.7307 & 0.3884 & 1 \\
\hline \multicolumn{7}{|l|}{ rs200069 } \\
\hline $\mathrm{C} / \mathrm{C}$ & $144(51 \%)$ & $355(49 \%)$ & $41(49 \%)$ & & & 1 \\
\hline $\mathrm{T} / \mathrm{C}$ & $111(40 \%)$ & $300(42 \%)$ & $36(43 \%)$ & & & $0.91(0.68-1.22)$ \\
\hline $\mathrm{T} / \mathrm{T}$ & $26(9 \%)$ & $63(9 \%)$ & $6(7 \%)$ & 0.8031 & 0.8422 & $1.02(0.62-1.67)$ \\
\hline $\mathrm{C}$ allele & $399(71 \%)$ & $1010(70 \%)$ & $118(71 \%)$ & & & 1 \\
\hline $\mathrm{T}$ allele & $163(29 \%)$ & $426(30 \%)$ & $48(3 \%)$ & 0.7704 & 0.8783 & $0.97(0.78-1.20)$ \\
\hline
\end{tabular}

Abbreviations: T2DM, type 2 diabetes mellitus; CHB, Han Chinese in Beijing; OR, Odd ratio

${ }^{a}$ Normal population from Han Chinese in Beijing (CHB) (data download from HapMap database)

${ }^{\mathrm{b}} p$-value from chi squared test; compared early onset T2DM patients with late onset T2DM patients

${ }^{c} p$-value from chi squared test; compared T2DM patients with normal population from CHB

${ }^{\mathrm{d}}$ Logistic regression model, univariate analyses

rs10121901 and the age at onset of T2DM in the Han Chinese population of Taiwan. Some previous studies have examined the influence of genetic heterogeneity on age at diagnosis of $\mathrm{T}_{2} \mathrm{DM}^{22,36-39}$; Molina et al ${ }^{22}$ found that the $A B C A 1 \mathrm{R} 230 \mathrm{C}$ variant is associated with early-onset T2DM in the Mexican population. The maximum allele frequency of the R230C variant however is less than $5 \%$ for the population in our study. We therefore investigated the association between SNP rs2230806, which is grouped by LD with rs9282541, and the age of onset of T2DM, but we did not find a significant result.

The results obtained in the present study have some limitations. First, information on age of onset was based on self-report questionnaires and was not validated by physicians; therefore, there could be an overestimated or underestimated bias. In addition, we only examined four polymorphisms, which do not represent all possible genetic variations of the $A B C A 1$ gene. Moreover, most of the previous studies have been conducted in non-Asian countries, and some previously examined polymorphisms (such as the $A B C A 1 \mathrm{R} 230 \mathrm{C}$ polymorphism) have very low frequencies among the Han Chinese population. Thus common polymorphisms in other populations could not be evaluated in our study. Further studies with a larger number of subjects in a more diverse population, especially Asian populations, are therefore needed to conclusively elucidate the association between genetic polymorphisms in $A B C A 1$ and different diabetic phenotypes. Functional analyses are also required to further characterize the role of $A B C A 1$ variation in the pathogenesis of T2DM. In conclusion, the findings of our study show that polymorphisms in the $A B C A 1$ gene are statistically associated with BMI and early-onset T2DM in a specific Taiwanese 
population.

Declarations: Wen-Ling Liao and Chieh-Hsiang Lu contributed equally to this work.

Acknowledgements: We gratefully acknowledge the National Research Programme for Genomic Medicine from the National Science Council, Taiwan, and the National Clinical Core for Genomic Medicine at Academia Sinica (grant number: NSC96-3112-B-001-010) for providing support services for data coordination, subject recruitment, and project management. This study was supported by research grants from the Biosignature Project, Academia Sinica, Taiwan; China Medical University Hospital (DMR-102045 and CMU102-N-01), Taichung City, Taiwan and from Ditmanson Medical Foundation Chia-Yi Christian Hospital Research Programme (R101-14), Chia-Yi City, Taiwan.

\section{REFERENCES}

1. Ogawa Y, Uchigata Y, Otani T, Iwamoto Y (2007) Proportion of diabetes type in early-onset diabetes in Japan. Diabetes Care 30, e30.

2. Chang CH, Shau WY, Jiang YD, Li HY, Chang TJ, Sheu WH, Kwok CF, Ho LT, et al (2010) Type 2 diabetes prevalence and incidence among adults in Taiwan during 1999-2004: a national health insurance data set study. Diabet Med 27, 636-43.

3. Song SH, Hardisty CA (2009) Early onset type 2 diabetes mellitus: a harbinger for complications in later years - clinical observation from a secondary care cohort. QJM 102, 799-806.

4. Wong J, Molyneaux L, Constantino M, Twigg SM, Yue DK (2008) Timing is everything: age of onset influences long-term retinopathy risk in type 2 diabetes, independent of traditional risk factors. Diabetes Care 31, 1985-90.

5. Chuang LM, Soegondo S, Soewondo P, Young-Seol K, Mohamed M, Dalisay E, Go R, Lee W, et al (2006) Comparisons of the outcomes on control, type of management and complications status in early onset and late onset type 2 diabetes in Asia. Diabetes Res Clin Pract 71, 146-55.

6. Lango $\mathrm{H}$, Palmer $\mathrm{CN}$, Morris $\mathrm{AD}$, Zeggini E, Hattersley AT, McCarthy MI, Frayling TM, Weedon MN (2008) Assessing the combined impact of 18 common genetic variants of modest effect sizes on type 2 diabetes risk. Diabetes 57, 3129-35.

7. Elbein SC (2009) Genetics factors contributing to type 2 diabetes across ethnicities. J Diabetes Sci Tech 3, 685-9.

8. Ma YQ, Thomas GN, Ng MC, Critchley JA, Chan JC, Tomlinson B (2003) The lipoprotein lipase gene HindIII polymorphism is associated with lipid levels in early-onset type 2 diabetic patients. Metabolism 52, $338-43$.
9. Mugabo Y, Li L, Renier G (2010) The connection between C-reactive protein (CRP) and diabetic vasculopathy. Focus on preclinical findings. Curr Diabetes $\operatorname{Rev}$ 6, 27-34.

10. Menzaghi C, Trischitta V, Doria A (2007) Genetic influences of adiponectin on insulin resistance, type 2 diabetes, and cardiovascular disease. Diabetes 56, 1198-209.

11. Hivert MF, Manning AK, McAteer JB, Florez JC, Dupuis J, Fox CS, O'Donnell CJ, Cupples LA, et al (2008) Common variants in the adiponectin gene (ADIPOQ) associated with plasma adiponectin levels, type 2 diabetes, and diabetes-related quantitative traits: the Framingham Offspring Study. Diabetes 57, 3353-9.

12. Al-Daghri NM, Al-Attas OS, Alokail MS, Alkharfy KM, Hussain T (2011) Adiponectin gene variants and the risk of coronary artery disease in patients with type 2 diabetes. Mol Biol Rep 38, 3703-8.

13. Attie AD, Kastelein JP, Hayden MR (2001) Pivotal role of ABCA1 in reverse cholesterol transport influencing HDL levels and susceptibility to atherosclerosis. J Lipid Res 42, 1717-26.

14. Oram JF, Vaughan AM (2006) ATP-Binding cassette cholesterol transporters and cardiovascular disease. Circ Res 99, 1031-43.

15. Brunham LR, Kruit JK, Pape TD, Timmins JM, Reuwer AQ, Vasanji Z, Marsh BJ, Rodrigues B, et al (2007) $\beta$-cell ABCA1 influences insulin secretion, glucose homeostasis and response to thiazolidinedione treatment. Nat Med 13, 340-7.

16. Villarreal-Molina MT, Aguilar-Salinas CA, RodríguezCruz M, Riaño D, Villalobos-Comparan M, CoralVazquez R, Menjivar M, Yescas-Gomez P, et al (2007) The ATP-binding cassette transporter A1 R230C variant affects HDL cholesterol levels and BMI in the Mexican population: association with obesity and obesityrelated comorbidities. Diabetes 56, 1881-7.

17. Kooner JS, Chambers JC, Aguilar-Salinas CA, Hinds DA, Hyde CL, Warnes GR, Gómez Pérez FJ, Frazer KA, et al (2008) Genome-wide scan identifies variation in MLXIPL associated with plasma triglycerides. Nat Genet 40, 149-51.

18. Acuña-Alonzo V, Flores-Dorantes T, Kruit JK, Villarreal-Molina T, Arellano-Campos O, Hünemeier T, Moreno-Estrada A, Ortiz-López MG, et al (2010) A functional ABCA1 gene variant is associated with low HDL-cholesterol levels and shows evidence of positive selection in Native Americans. Hum Mol Genet 19, 2877-85.

19. Flores-Dorantes T, Arellano-Campos O, Posadas-Sánchez R, Villarreal-Molina T, Medina-Urrutia A, Romero-Hidalgo S, Yescas-Gómez P, Pérez-Méndez O, et al (2010) Association of R230C ABCA1 gene variant with low HDL-C levels and abnormal HDL subclass distribution in Mexican school-aged children. Clin Chim Acta 411, 1214-7.

20. Daimon M, Kido T, Baba M, Oizumi T, Jimbu Y, 
Kameda W, Yamaguchi H, Ohnuma H, et al (2005) Association of the ABCA1 gene polymorphisms with type $2 \mathrm{DM}$ in a Japanese population. Biochem Biophys Res Comm 329, 205-10.

21. Tang C, Oram JF (2009) The cell cholesterol exporter ABCA1 as a protector from cardiovascular disease and diabetes. Biochim Biophys Acta 1791, 563-72.

22. Villarreal-Molina MT, Flores-Dorantes MT, ArellanoCampos O, Villalobos-Comparan M, Rodríguez-Cruz M, Miliar-García A, Huertas-Vazquez A, Menjivar M, et al (2008) Association of the ATP-binding cassette transporter A1 R230C variant with early-onset type 2 diabetes in a Mexican population. Diabetes 57, 509-13.

23. American Diabetes Association (2007) Standards of medical care in diabetes-2007. Diabetes Care 30 Suppl 1, S4-S41.

24. Porchay-Baldérelli I, Pean F, Emery N, Maimaitiming S, Bellili N, Travert F, Mohammedi K, Roussel R, et al (2009) Relationships between common polymorphisms of adenosine triphosphate-binding cassette transporter A1 and high-density lipoprotein cholesterol and coronary heart disease in a population with type 2 diabetes mellitus. Metabolism 58, 74-9.

25. Cohen JC, Kiss RS, Pertsemlidis A, Marcel YL, McPherson R, Hobbs HH (2004) Multiple rare alleles contribute to low plasma levels of HDL cholesterol. Science 305, 869-72.

26. Frikke-Schmidt R, Nordestgaard BG, Jensen GB, Tybjærg-Hansen A (2004) Genetic variation in ABC transporter A1 contributes to HDL cholesterol in the general population. J Clin Investig 114, 1343-53.

27. Hodoğlugil U, Williamson DW, Huang Y, Mahley RW (2005) Common polymorphisms of ATP binding cassette transporter A1, including a functional promoter polymorphism, associated with plasma high density lipoprotein cholesterol levels in Turks. Atherosclerosis 183, 199-212.

28. Porchay I, Péan F, Bellili N, Royer B, Cogneau J, Chesnier MC, Caradec A, Tichet J, et al (2006) ABCA1 single nucleotide polymorphisms on highdensity lipoprotein-cholesterol and overweight: the D.E.S.I.R. study. Obesity 14, 1874-9.

29. Ma XY, Liu JP, Song ZY (2011) Associations of the ATP-binding cassette transporter A1 R219K polymorphism with HDL-C level and coronary artery disease risk: a meta-analysis. Atherosclerosis 215, 428-34.

30. Yancey PG, Bortnick AE, Kellner-Weibel G, de la Llera-Moya M, Phillips MC, Rothblat GH (2003) Importance of different pathways of cellular cholesterol efflux. Arterioscler Thromb Vasc Biol 23, 712-9.

31. Sartipy P, Loskutoff DJ (2003) Expression profiling identifies genes that continue to respond to insulin in adipocytes made insulin-resistant by treatment with tumor necrosis factor-alpha. J Biol Chem 278, 52298-306.

32. Wang Chung-Hsing LW-D, Bau Da-Tian Chou I-Ching Tsai Chang-HaiTsai Fuu-Jen (2013) Appearance of acanthosis nigricans may precede obesity: An involvement of the insulin/IGF receptor signaling pathway. BioMedicine 3, 82-7.

33. Xu M, Zhou H, Wang J, Li C, Yu Y (2009) The expression of ATP-binding cassette transporter A1 in Chinese overweight and obese patients. Int J Obes 33, 851-6.

34. Moon MH, Seol JW, Seo JS, Jeong JK, Lee YJ, Kim IS, Jackson C, Sambrook P, et al (2010) Protective effect of hypoxia on bisphosphonate related bone cell damage. Mol Med Rep 3, 869-75.

35. von Eckardstein A, Sibler RA (2011) Possible contributions of lipoproteins and cholesterol to the pathogenesis of diabetes mellitus type 2. Curr Opin Lipidol 22, 26-32.

36. Gragnoli C (2008) CHOP T/C and C/T haplotypes contribute to early-onset type 2 diabetes in Italians. J Cell Physiol 217, 291-5.

37. Ma L, Hanson RL, Que LN, Guo Y, Kobes S, Bogardus C, Baier LJ (2008) PCLO variants are nominally associated with early-onset type 2 diabetes and insulin resistance in Pima Indians. Diabetes 57, 3156-60.

38. Prudente S, Scarpelli D, Chandalia M, Zhang YY, Morini E, Del Guerra S, Perticone F, Li R, et al (2009) The TRIB3 Q84R polymorphism and risk of earlyonset type 2 diabetes. J Clin Endocrinol Metabol 94, 190-6.

39. Liao WL, Chen CC, Chang CT, Wu JY, Chen $\mathrm{CH}$, Huang YC, Tsai CH, Tsai FJ (2012) Gene polymorphisms of adiponectin and leptin receptor are associated with early onset of type 2 diabetes mellitus in the Taiwanese population. Int J Obes 36, 790-6. 